\title{
REVIEW OF EXHIBITION
}

The Triumph of Marriage: Painted Cassoni of the Renaissance (Isabella Stewart Gardner Museum, Boston, 16 October 2008-18 January 2009; The John and Mable Ringling Museum of Art, Sarasota, 14 February-17 May 2009). Cristelle Baskins, Adrian W. B. Randolph, Jacqueline Marie Musacchio and Alan Chong, The Triumph of Marriage: Painted Cassoni of the Renaissance. Boston: Isabella Stewart Gardner Museum in association with Gutenberg Periscope Publishing, 2008. 182 pp. with numerous illus. (most in colour). $\$ 45.00$, ISBN 978-1934772867 (hb).

Art and Love in Renaissance Italy (The Metropolitan Museum of Art, New York, 11 November 2008-16 February 2009; The Kimbell Art Museum, Fort Worth, 15 March-14 June 2009). Andrea Bayer, (ed.), Art and Love in Renaissance Italy. New York: Metropolitan Museum of Art and New Haven/London: Yale University Press, 2008. 392 pp. with 375 illus. (300 in colour). \$65.00, ISBN 978-1588393005 (hb); \$45.00, ISBN 978-1588393012 (pb).

From one small space showing fourteen cassone fronts and two side panels in Boston to ten rooms filled with over 150 objects in New York, the domestic arts of Renaissance Italy were recently on splendid display in two overlapping exhibitions. Earlier in the year (27 March-27 July 2008), the Bowdoin College Museum of Art organized the exhibition 'Beauty and Duty: The Art and Business of Renaissance Marriage', and 'Love and Marriage in Renaissance Florence: The Courtauld Wedding Chests' was on show in London's Courtauld Gallery from 12 February to 17 May 2009. All of these well-crafted exhibitions were partly spurred by such books as Peter Thornton's groundbreaking The Italian Renaissance Interior, 1400-1600 (1991) and the innovative exhibition 'At Home in Renaissance Italy', mounted by the Victoria and Albert Museum in 2006-7. ${ }^{1}$ They evince the revival of interest in contextualizing Italian domestic art within Renaissance material culture. What intellectual currents like feminist analysis and cultural studies have wrought in the field of contemporary and popular culture is also having a salutary effect on the broad range of artifacts from a period once defined as the epitome of European High Art.

The 'Triumph of Marriage' at the Isabella Stewart Gardner Museum was inspired by its own newly cleaned, candy-coloured cassoni panels by Francesco Pesellino depicting the allegorical pageant of Petrarch's triumphs (Love, Chastity and Death on one, Fame, Time and Eternity on the other), which was one of the more common subjects

\footnotetext{
${ }^{1}$ Reviewed in this journal by Aislinn Loconte, Renaissance Studies 21 (2007), 703-12.
} 
for the fronts of large fifteenth-century storage chests, traditionally associated with weddings. The title, however, was politically insensitive and anachronistic. Absent from Petrarch's poem and not consistently evident in the exhibition, the 'Triumph of Marriage' was not a pictorial theme of the time. Other subjects in Boston included an independent Triumph of Chastity and a relatively small and late Triumph of Venus attributed to Pseudo-Granacci (c. 1500), but also allegorical figures accompanied by historical exemplars (seven virtues on one panel, and seven liberal arts on a second). Most paintings represented 'triumph' by way of historical processions, including episodes from Frederick III's sojourn in Italy during 1452, as well as the military triumphs of the ancient Roman heroes Alexander, Scipio and Camillus. The theme was expanded to include a battle that resulted in a triumphal procession (Alfonso of Aragon's siege of Naples (Fig. 1), with the companion panel showing the celebratory procession only on show later at the Ringling) and a narrative laid out in the form of a procession (Tarquin and Tanquil entering Rome). Lastly, two captivating Sienese panels showed the love story and wedding celebration of Antiochus and Stratonice.

In the earlier part of the fifteenth century, cassoni with a bride's trousseau were paraded through Tuscan city streets to her husband's home in what the preacher Bernardino of Siena regarded as a new kind of 'triumph'. From around 1460 they were apparently no longer carried in procession but simply commissioned by the groom's family to furnish the new couple's abode. It is not clear what visual changes resulted from this shift, but similarly elongated narrative panels from later in the century are often identified as spalliere, wall paintings set above wooden elements like day beds or wainscoting. The Camillus scene in Boston and several panels in New York were of this later sort, and some may have been commissioned for refurbishments rather than nuptials. What both exhibitions highlight is the centrality of the issue of the marital rituals and institution to Renaissance material culture, while opening up new avenues for future research. Most surviving chests, for example, are pastiches reassembled during the nineteenth and early twentieth centuries for a new collectors' market. One of the few considered original, the 'Trebizond cassone' in the Metropolitan Museum (cat. 56), was shown by the meticulous research of conservators presented during that exhibition's Study Day to be a composite from several chests.

Panels initially housed on chests near the floor or fixed high on walls were, in both exhibitions, treated as traditional works of art displayed at adult eye level, but the Boston curators thoughtfully showed them unframed (when possible) and positioned on a specially-constructed ledge rather than hanging. In several cases the bare wood around a painting's edge was visible, reminding viewers of its objecthood, fragmentary state and subsequent history. In the middle of the room, a frontal and two side panels (all from the Worcester Art Museum) were applied to a near eye-level box to give some sense of the original structure. The Gardner's compact, jewel-like exhibition thus provided an invaluable opportunity to inspect and compare the works closely, analyzing their particular characteristics and strategies, especially since a number of the works were recently cleaned and almost all were in very good condition. Usually, cassoni are notoriously difficult to study, most hard of access, many in semi-ruined condition, and poorly reproduced. Reproductions in the catalogue were of high quality, though the welcome use of fold-out pages was rarely exploited to full advantage. 


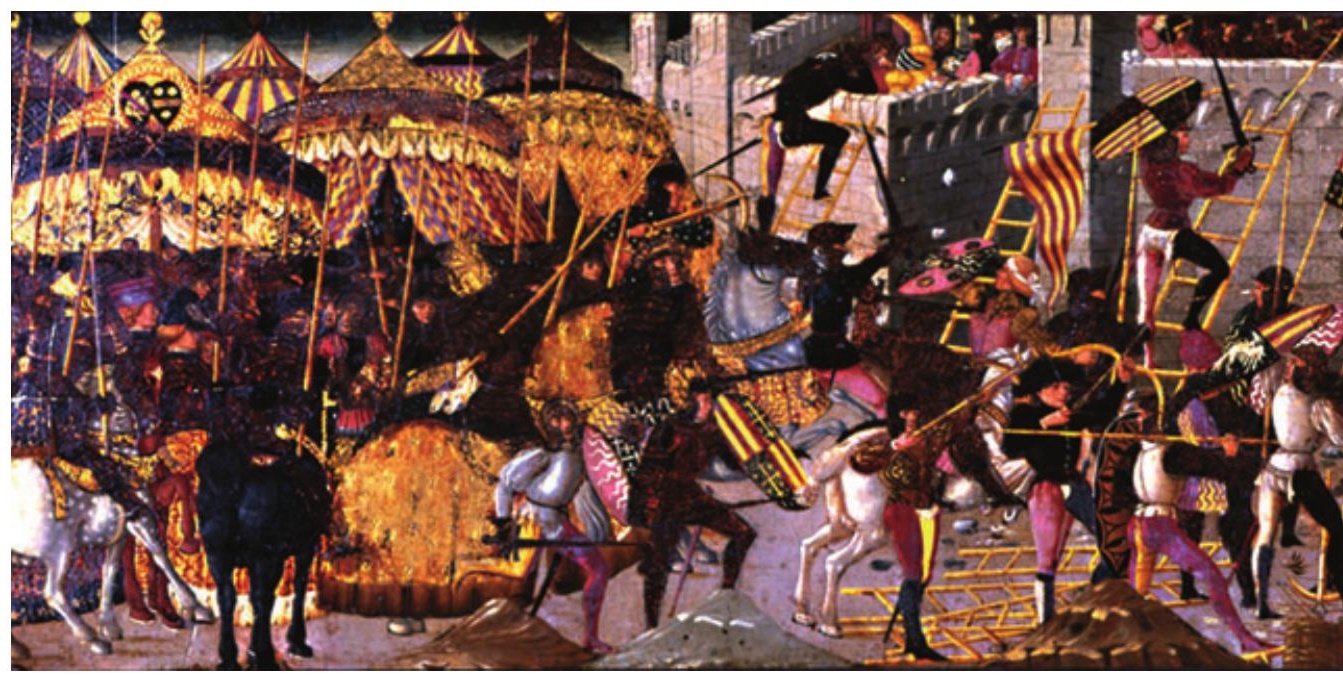

Fig. 1 Florentine painter, The Siege of Naples, 1460s, tempera and gold on wood, $41.4 \times 165.1 \mathrm{~cm}$, collection of The John and Mable Ringling Museum of Art, bequest of John Ringling, 1936, SN14

Inevitably, questions about modes of Renaissance viewing and interpretation were raised by the cassoni. Their often minute details and small inscriptions were clearly meant to be scrutinized, if not in everyday life from floor level then at least at the time they were commissioned and presumably put on display (in a procession, or at a wedding banquet, events often represented on cassone paintings). Humorous details like the defecating horse in the foreground of the Triumph of Scipio (cat. 13), the dog in the background of the Triumph of Camillus jumping up to bite the genitals of a horse (cat. 12), or the foreshortened head and arms of a man dropping a stone over the side of the fortified walls at the very top of the composition in the Siege of Naples (Fig. 1) can only be appreciated close-up. On the other hand, these panels also create an attractive surface pattern from farther away. In the Siege, lances, ladders, and banners angled in different directions and the multi-coloured hose of the soldiers creates a sense of the chaos and conflict of battle, especially in comparison to the vertical lances and decoratively ornamented tents of the pre-battle scene to the left and the submission, when Renee retreats, on the right. Colour, line, pattern and ornament contribute both to the narrative and to the decorative effect.

Several catalogue essays consider the serious 'messages' conveyed by the chests in general, ranging from the straightforwardly didactic (Musacchio) to the 'contradictory or paradoxical' (Baskins) to what Randolph called 'a liminal zone for working through and around the cultural tensions of marriage'. The assumption that such objects were addressed primarily, even exclusively, to female viewers is being modified. Many of the exhibited works, such as the siege, seem neither especially addressed to women, nor particularly hortatory. Like Lorenzo de' Medici in his Comento, Vasari praised the variety of subjects in domestic painting (battles, landscapes, perspectives, myths and 


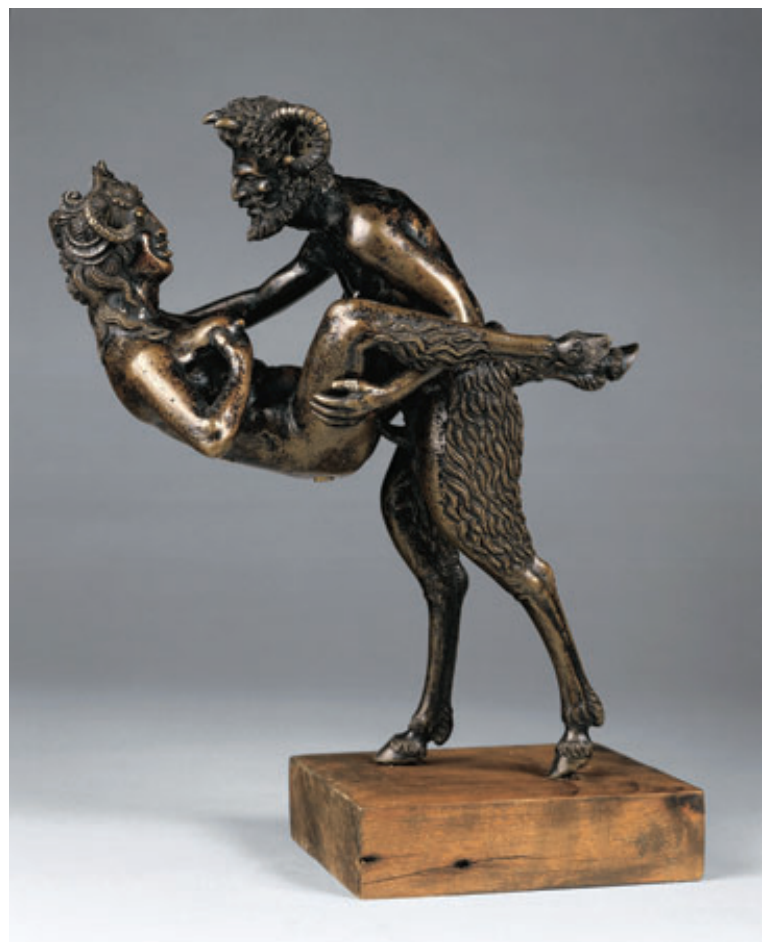

Fig. 2 Desiderio da Firenze (attrib.), Satyr and Satyress, after 1524 (?), bronze, $27 \mathrm{~cm}$ (height), Musée National de la Renaissance, Château d'Écouen (E.Cl. 2752a, b)

marriage vows. Since the heads are generic, perhaps the patron was not a family member but a notary who used it at many weddings. The legal function usefully reminds us that pre-Tridentine marriage did not require a priest and was contractual, chiefly about economic, political and dynastic alliance, entailing the exchange of funds and goods as well as the transfer of a woman's body that was expected to produce heirs. The handclasp and statement of fede signified any contract, including an avowal of friendship between men, and the joined hands also seen in an exhibited footed bowl and a plate were not differentiated by gender. The bowl (cat. 17) also showed the coat of arms of the Florentine Capitano del Popolo, an authority likely to witness public acts like affirmations of peace and conciliation; perhaps it was used for a symbolic washing of hands during such rituals.

Some objects in the exhibition were not exclusively or primarily connected to weddings or marriage, let alone to only one particular, personal event. Civic imagery was adapted in small, colourful della Robbia ware versions of Florence's public statue of the personification of Dovizia or Abundance, for instance. The one on display (cat. 48) wittily has a slimy green reptile clamber up the white base so that the dignified maiden's eruption is anticipated; more than a stock gesture toward fertility is at work. The 'Adimari cassone' (cat. 134) is actually a spalliera panel and the emphatic 
presence of the Florentine Baptistery along with musicians marked by civic banners suggests that it commemorates not a wedding but a public dance to honour visiting dignitaries or another contemporary event akin to the pictorial interest in Emperor Frederick a decade or less later.

Although some of the catalogue tends to stress personal romance, courtship was public, visible discourse and arranged marriage was the usual mode for the elite who could afford to commission and preserve the objects on display. Rather than a timeless, emotive bond of 'love', the conventions of courtly love were especially evident in the adjoining room's collection of various decorative arts such as glassware, rings, pendants, girdles and small caskets.

The ensuing room concentrated on portraits of couples, such as Filippo Lippi's disconcertingly pressurized pair from the Metropolitan's collection, the bedecked state portraits of Giovanni II Bentivoglio and spouse Ginevra Sforza from the National Gallery of Art in Washington DC and, from the Hermitage, Lorenzo Lotto's portrayal of a husband pointing to a squirrel while the wife holds a lap dog and a storm rages in the distance. Straightforward romance and happiness seem remote, overcome by self-conscious display of qualities like loyalty, princely authority or morality for visitors, outsiders and heirs.

Everett Fahy's essay in the catalogue struck a welcome note of caution about the 'marriage portrait'. Such pairs often resulted anywhere from two to fifteen years after the date of a wedding, which brings healthy scepticism to the enterprise, tempting for a host of objects, of pinpointing commissions and hence dates to the nuptial moment. A handclasp and bestowal of a ring forged a contractual obligation, but the crucial act of consummation was often delayed, especially while brides were young. When a husband 'led' (the Italian verb was menare) the bride to his household was a public, sexual and significant moment. Pictorial production might result only after proof of sexual performance, or at the time of a birth, or a spouse's death. Cases such as three similar versions of a pair portrayed by the Ghirlandaio workshop (the Huntington's pair was on display, cat. 122), in which only the male figure alters appreciably, indicate that recognizable, individualized faces were not necessarily paramount, especially in the case of young female beauties. Alcoves behind the women display objects like a book, jewels and a needle, identified as 'marriage gifts' with no evidence, for they could just as easily be her own dowry or objects acquired since the marriage. Such objects were frequently inherited or passed on from a friend or relative, in which case they record women's networks of gifting, support and agency.

Several paintings represent widows, most notably Leandro Bassano's view of a widow praying against the backdrop of a framed painting of the Birth of the Virgin, from a private collection and dated to the 1590s (cat. 133). This was the show's chief acknowledgment of religious matters, here emphasizing a woman's important role as a guardian of familial piety. An adjoining room with dimmed lighting contained an odd assortment, textiles with heraldry, embroidery, tarocchi cards, an illuminated epithalamium from the Sforza court of Milan, a few printed books and Alessandro Allori's oil-on-copper portrait of Bianca Cappello, mistress then wife of Francesco de' Medici.

Birth and childhood was the topic of a room filled with childbirth bowls and platters, a cradle, a few portraits of infants and eight deschi (polygonal trays, decorated on both 
front and back, sometimes described in inventories as 'da parto', for birth). It was astounding to see so many deschi gathered in one place, which clarified how intriguing and visually delightful they are. As with cassoni, thematic variety was striking, from Triumphs of Venus, Fame or Chastity, to fictional scenes such as the Garden of Love and episodes from a Boccaccio love story, to contemporary views of a birth chamber or youths playing hand games in a piazza. The exhibition's sweep from birth to death ultimately created a diffusion and loss of focus. It can be asked: what interior decoration is not 'marital' in family palaces? What do we learn that is new by creating the category of 'marriage painting'? And: what does 'love' have to do with it?

While the exhibition focused on the life cycle of a marriage, little attention was paid to the life cycle of an object. For instance, a desco might eventually pass into storage or be relegated to a passageway, as a 'desco da donne di parto, dipinto' was in Lorenzo de' Medici's inventory of $c .1492$ (fol. 52 r). Objects were loaned, recirculated or sold, then purchased on the second-hand market; others were copies, or available on the open market, finished with the addition of coats of arms but not otherwise personalized in a way that can lend to them a sentimental reading. Audiences and viewing circumstances changed over time. Household goods like a cradle were not necessarily nuptial or amorous. How does one define and identify 'marital' art? Impaled arme did not appear only at the wedding, and they could signify a widow, or a wife exercising her own patronal agency. Objects entered households by a variety of means, at such times as redecoration or as birthday gifts or when noblewomen sent back to their agnatic family portraits of themselves and their children. Inspired by this exhibition, further research can consider what distinctions might apply to nuptial, marital, natal, maternal, conjugal and household goods. When, for example, do presumed 'wedding gifts' become a woman's possession and hence are no longer best understood as nuptial? Why assume that any sumptuous costume must be bridal?

These rooms were followed by a large space hung with cassoni and spalliere but with the centre empty of all but a modern bench. Topical variety was even more evident in New York than in Boston. On cassone fronts, Trebizond was conquered in a scintillating display, Esther was feasted lavishly, the Argonauts journeyed in great detail over two panels, and on two inner lids putti trumpeted on armorial dolphins or Cupid engaged in a gentle tug-of-war with reclining Venus for possession of a rose garland (though the authenticity of the latter panel, cat. $58 \mathrm{~b}$, may be dubious). Bright colour aided by gilding ensured clarity and gaiety, and the narrative scheme frequently resorted to figural repetition, all the more to engage viewers in the episodic, drawn-out nature of the tale. Psyche, for example, recurs seven times in one spalliera painting (cat. 136). The highlight in this section was the gathering together of the three Tornabuoni-Albizzi panels of 1487, each painted by a different artist and divided now between the Musée des Arts Décoratifs in Paris and the Mari-Cha Collection (cat. 140). First the Argonauts depart on their epic adventure, then Jason faces challenges in Colchis, and finally he weds Medea, a fitting analogy for the rite of passage into manhood culminating in marriage, despite the savage story that ensues, but is left out of the picture.

Rather than 'triumph,' the best metaphorical comparison between Renaissance marriage and the imagery on many chests, spalliere and some deschi might rather be 
the battle of the sexes, a trope readily available ever since Ovid. Battles and other military or chivalric exploits like sieges, jousts and epic travels were the subject of many of the exhibited domestic furniture paintings, reinforcing gender norms for an ideally young male and female audience raised on chivalric romances. As much as or more than fertility, themes of antagonism, alliance and integration are signalled by the finger-biting, penis-pulling, pissing, tussling activities of male putti seen on several of the deschi (cat. 69, 71, 72) and in a polychrome terracotta group made by the Florentine Master of the Unruly Children around 1500 (cat. 47). Amusement and sexual innuendo were fitting during the celebrations of nuptials and births, and for such uses as the recovery of a parturient mother. 'Talismatic' encouragement of a wife's fertility has probably been over-emphasized, at the expense of appreciating her other duties and life-stages as well as a household's interest in its economic prosperity, social standing, display of wealth and felicitous decoration. The disruptive arrival of a stranger from another family and sometimes another city is echoed by such themes as the Rape of the Sabines or the Queen of Sheba's visit to Solomon (Fig. 3), which thus has anthropological significance beyond ecclesiastical allegory or the decorative emphasis on exotic, lavish detail.

Before moving to paintings in the final room, two low-lit rooms featured 'profane love', that is, explicit sexual imagery that was dissociated from marriage, characterized in the show's introductory wall text as an 'important detour from the path of marriage and family' and in the catalogue's foreword as a 'detour' into 'the secret world of Renaissance erotica'. A kind of heterosexual, modern and marital closet was implied, for the 'hidden' and 'illicit' was conflated with the 'erotic'. It was assumed, for example, that mistresses were shameful (despite their widespread presence in courts) and wives were jealous, that sexual wit could not be part of marital discourse, and that a shallow rebate behind a mirror must have contained an 'illicit image' that transformed 'this otherwise innocent household object' (cat. 115). Although common in Renaissance texts and practice, homoeroticism was under-represented, implicitly by a copy of Parmigianino's seductive Cupid Carving his Bow and overtly by two drawings of Apollo's relations with a youth (by Giulio Romano and Perino del Vaga), and no female-female physical intimacy was recognized.

Polarities, more than overlap, simultaneity or multivalence often informed the catalogue, and the modernist divide between public and private, official and clandestine, was especially strange given issues like the public, witnessed and civic nature of marriage, the legal importance of consummation, the dissemination in multiple prints of erotica, and the degree to which consumers of erotica or clients of courtesans were married men. Sexual witticisms and pleasures were often present in the 'licit' sections. Darker, inlaid wood accentuated the clothed woman's nipples on a musical instrument for instance (cat. 45), and a pharmacy jar for respiratory ailments was identifiable because it was decorated with a male lover placing his hand on a woman's bared chest (cat. 20). Further, it is worth noting that an expulsive 'cough' or 'laugh' was a doubleentendre for orgasm, as was the 'death' welcomed in the love poem woven on a sixteenth-century belt (cat. 55). To create separate spheres between images deemed respectable versus those considered obscene in modern times reinstates anachronistic standards of smuttiness and shame. 


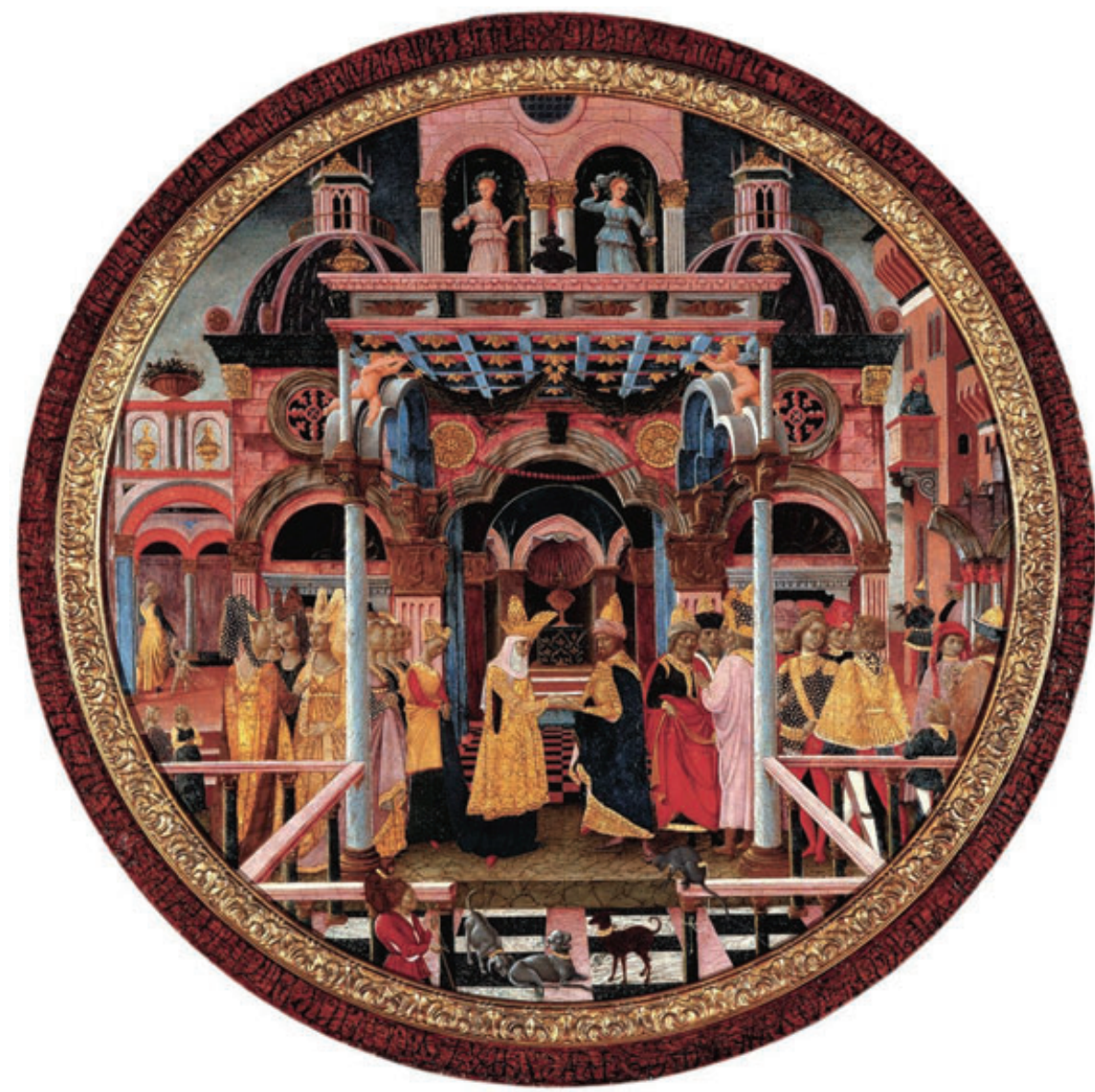

Fig. 3 Workshop of Francesco del Cossa, Childbirth Tray (Desco da Parto) with The Meeting of Solomon and the Queen of Sheba, c. 1470-73, tempera, gold, oxidized silver leaf on panel, $92.3 \mathrm{~cm}$ (diameter), The Museum of Fine Arts, Houston, The Edith A. and Percy S. Straus Collection (44.574)

Nevertheless, it was crucial that the theme of 'art and love' was enriched by sexual elements, a daring move for such an establishment institution and of particular value to scholars, but also illuminating for other attendees given the history of censorship and inaccessibility. Two ink drawings of Parmigianino's had suffered defacement but the erections of Priapus and of a male figure were now discernible (cat. 96a, 97). For the first time, alongside the British Museum's nine fragments related to the Modi engravings of $c .1525$ stood the 'Toscanini Volume' (cat. 100), a woodcut version dated to the 1550 s that is the key evidence for reconstructing the original series but still in private hands despite its placement on the market several years ago. First published only in 2007 by James Grantham Turner, a large (seventeenth-century?) print of the Triumph of the Phallus after a drawing by Francesco Salviati exuberantly imagined a 
gigantic phallus processed toward a vaginal 'arch', accompanied by revelling putti, frenzied women and numerous trophies stripped from their clients (cat. 102). It was possible to appreciate the fine, shimmering quality of Caraglio's engravings in the 'Loves of the Gods' series, usually obscured by poor reproduction, often only of variants or copies, but here represented by seven of the twenty originals. The maiolica pieces in this section included the Ashmolean's humorous plate of a head composed entirely of phalli (a dickhead, 'una testa de cazi' according to an inscription), acquired in 2003 (cat. 110).

Only after this material did the representation of female nudity in the last room make sense, even though the attempt to situate all the paintings within marriage was not entirely convincing. One wonders if bachelors ever commissioned a single secular painting. Subdivisions in the final room included 'illustrious women' and 'belle donne' (Giorgione's 'Laura' and two of Palma il Vecchio's delectable ladies for the latter), but the exhibition's progress narrative concluded with the sixteenth-century rise of the independent painting, 'freed from functional purposes and imbued with far greater poetic sensibilities', according to the wall text. 'Belle donne' also appeared on maiolica displayed in earlier rooms, and famous women like Beccafumi's Penelope panel could form part of a room's permanent ensemble, like spalliere, so the triumph of poesia and so-called high art was presumably claimed primarily for the room's 'mythologies and allegories'. Two oil-on-canvas pictures by Paris Bordon and two by Titian were joined by Tintoretto's amusingly mocking Venus and Mars Surprised by Vulcan (Fort Worth only), an intriguing if damaged image of three women identified as an 'Allegorical Wedding Picture' attributed to Cariani, and Lorenzo Lotto's Venus and Cupid from the Metropolitan's own collection (cat. 148). The last was, in a sense, the raison d'être of the show, long said to be a marriage painting. Of what, then, is the Lotto image paradigmatic? Amongst other things, it uses sexual puns (such as vulval shell, entwined vines, 'pissing' Cupid, plucked rose) and the humour is accentuated by his grin and her smile. Mythology is rendered in a merry rather than somberly allegorical key.

From the intimate to the gargantuan, the two innovative exhibitions raised fascinating issues about the domestic arts. The future task set by both is to continue working away at nuanced comprehension, no longer dismissing the objects as 'decorative' and meaningless, nor reducing them to bourgeois auguries of personal love, fertility or motherhood, nor thinking that the only way to recuperate them is to regard them as allegorical, learned or moralizing. Enjoyable factors like sensuality, visual delight, irony, charm and humour emerged as key features of elite Renaissance interiors.

University of Michigan, Ann Arbor

Patricia Simons

University of Massachusetts, Amherst

Monika Schmitter 